\title{
PESQUISA EM GESTÃO DE RECURSOS HUMANOS NOS ANOS 1990: UM ESTUDO BIBLIOMÉTRICO
}

\section{RESUMO}

Neste artigo é usada análise bibliométrica para entender a influência de autores e instituições na produção acadêmica em Recursos Humanos no Brasil na década de 1990, bem como para mapear o comportamento de auto-citações e citações à própria instituição dos autores que produziram no período. O estudo levantou, nos 290 artigos de RH publicados na década de 1990 (1991 a 2000) nos anais do Enanpad, a constituição, origem e padrão de interrelação de todas as citações, autores e instituições que publicaram e foram citados na área. No total, analisou-se os padrões bibliométricos de 5.814 citações, que compreendiam 342 autores, advindos de 51 instituições. Os resultados mostram uma área com alto índice de auto-citação e endogenia, e com uma elevada incidência de citação de jornais, revistas e autores estrangeiros e não acadêmicos. O artigo termina oferecendo ao campo sugestões para desenvolvimento e debate, a partir dos seus resultados e sua comparação com trabalhos anteriores analisando a mesma base amostral.

\section{Miguel P. Caldas \\ Loyola University New Orleans}

\section{Tatiana Tinoco}

FGV-EAESP

\begin{abstract}
This research proposes the use of bibliometric analysis to understand the influence of authors and institutions in the human resources academic literature produced in Brazil throughout the 90's (1991 a 2000). The study mapped out, within the 290 articles published in the Enanpad proceedings, the constitution, origin, and relationship patterns of all citations, authors and institutions that were cited in the period's published articles. The bibliometric pattern of 5814 citations was analyzed, resulting 342 authors and 51 institutions. The results show an area with high level of selfcitation and endogeny and elevated incidence of references to newspapers, magazines and foreign, non-academic authors. This study ends offering to the area suggestions for development and debate coming from the results and the comparison with prior studies using the same sample base.
\end{abstract}

PALAVRAS-CHAVE Recursos Humanos, produção científica, análise bibliométrica, citações. KEY WORDS Human Resources, academic production, bibliometric analisys, citations. 


\section{INTRODUÇÃO}

"Freqüentemente eu cito a mim mesmo. Isso torna mais instigante a minha conversação". (George Bernard Shaw)

Nos últimos anos, um número crescente de áreas e autores (e.g. Organizações [Machado-da-Silva et al., 1990; Bertero e Keinert, 1994]; Marketing [Vieira, 1998, 1999, 2000, 2003; Perin et al., 2000; Botelho e Macera, 2001]; Produção [Bignetti e Paiva, 1997], Operações [Arkader, 2003]; Tecnologia de Informação [Hoppen et al., 1998]; Finanças [Leal et al., 2003]) têm-se dedicado à análise da produção acadêmica nacional. O objetivo tem sido verificar a qualidade do que é produzido em cada área de conhecimento da administração; no geral, tem-se mostrado que há problemas sérios e reincidentes em todas as áreas, como a falta de solidez metodológica (fato também observado por Quintella (2003) em sua comparação entre o Enanpad e o encontro da Academy of Management), base teórica importada, falta de relevância da pesquisa realizada e autoria com baixa diversidade de origem.

Recentemente, na área de Recursos Humanos, esse tipo de análise também ganhou atenção. Caldas, Tonelli e Lacombe (2002) analisaram a produção da área no Enanpad entre 1990 e 2001, enquanto Tonelli et al. (2003), mais recentemente, incluíram, além do Enanpad, a produção de $\mathrm{RH}$ veiculada nos principais periódicos nacionais. Os resultados desses dois trabalhos indicam que o escopo temático da área é contestado pelo recente crescimento do campo de comportamento organizacional; que sua base epistemológica é funcionalista; que sua base metodológica é frágil, com predominância de estudos de caso ilustrativos de teorias já bem estabelecidas; e que a maior parte da produção da área (65\% ou mais) é proveniente de poucos programas de pós-graduação.

Embora importantes sinais de alerta, esses estudos deixam de fazer uma análise mais aprofundada dessa produção, seja em termos de conteúdo, seja em termos do trajeto de influência de autores, instituições e publicações que serviram de base à produção acadêmica de recursos humanos no período. Em outras palavras, esses estudos não analisaram as citações dos artigos publicados, deixando de identificar, com maior riqueza de detalhes, em "quem" ou "em que" se baseou essa literatura para criar conhecimento, bem como "de que maneira esse uso foi feito". Esse tipo de análise ("citacional" ou "bibliométrica") é normal e corrente em outros países, e é usado como elemento para entender como um determinado campo do conhecimento foi influenciado por determinados autores, instituições, países, linhas de pen- samento e veículos (Garfield, 1955,1998; Leydesdorff, 1998; Kostoff, 1998).

Já se tentou fazer análise citacional no Brasil. $\mathrm{Na}$ área de Economia, as pesquisas de Azzoni $(1998,2000)$ visaram avaliar a produtividade dos autores, o ranking de revistas mais importantes e o desempenho das instituições acadêmicas da área. Já no campo da Administração, Vergara (1995, 1996, 1998), por exemplo, analisou a nacionalidade dos autores citados na área de Organizações entre 1989 e 1998 nos artigos publicados na RAE, RAP, RAUSP e no Enanpad, concluindo que, apesar do crescimento do número de artigos publicados e citados, a base de citações tem se mostrado predominantemente estrangeira - estadunidense, em particular -, o que é um problema quando se pensa na proximidade entre a pesquisa e a realidade nacional.

Contudo, na área de Administração, tanto os autores focados na produção de textos em RH (Caldas, Tonelli e Lacombe, 2002; Tonelli et al., 2003) quanto os focados em trabalhos de citação (Vergara, 1995, 1996, 1998; Bignetti e Paiva, 2002) interromperam seus esforços na realização de uma análise mais aprofundada sobre os autores, veículos e instituições mais citados em RH no Brasil, bem como no levantamento dos padrões de referência dos seus principais autores e instituições de origem. Sem esse tipo de análise, tais estudos e contribuições deixam de evidenciar algumas importantes limitações e potencialidades de melhoria da área e de sua produção científica.

Uma dessas limitações refere-se a uma prática de não reconhecimento e aproveitamento, feita por alguns autores da área de RH, da produção recente de outros colegas que, em programas diferentes dos seus, têm desenvolvido trabalhos semelhantes. Outro ponto importante refere-se ao fato de que a produção desses mesmos autores ignorados é amplamente citada por eles próprios e por colegas da mesma instituição, formando "bolsões" de autores que se autocitam e que se isolam da produção feita sobre o mesmo assunto em outros programas ou instituições. Sem essa análise, não se consegue verificar se a área lê a si própria; se ela foge do processo entrópico que a endogenia (em termos de excessiva autocitação ou referência excessiva à produção do próprio programa) pode provocar; e se ela está evoluindo no processo de criação de redes interinstitucionais que a área de Administração tanto tem advogado recentemente no Brasil (Fischer, 1993), evitando que a mesma pesquisa seja feita em universidades diferentes, como é classicamente encontrado em campos científicos (Martyn, 1965; Cole e Cole, 1973).

O objetivo deste trabalho é contribuir para o preenchimento dessa lacuna na análise da produção científica 
em RH no Brasil, nos últimos anos. Para tanto, usamos análise bibliométrica de modo a entender a influência de autores e instituições na produção acadêmica em Recursos Humanos no Brasil, bem como o comportamento de autocitações e citações à própria instituição dos autores e programas que produziram na década de 1990. Em termos específicos, esse tipo de análise objetivou: (a) examinar o nível de autocitação e endogenia na construção do conhecimento na área; (b) identificar quem foram os autores, veículos e instituições mais citados; (c) levantar os padrões de referência dos principais autores - e de suas instituições de origem - da área no período; e (d) oferecer ao campo sugestões práticas para desenvolvimento e debate, a partir dos resultados da pesquisa e de sua comparação com trabalhos anteriores que analisaram a mesma base amostral.

Do ponto de vista empírico, o estudo levantou e analisou os padrões bibliométricos básicos (constituição, origem e padrão de interrelação) de todas as citações, autores e instituições que publicaram nos anais do Enanpad e foram citados nos 290 artigos publicados na década de 1990 (1991 a 2000) na área de Recursos Humanos. No restante do artigo, discutem-se a fundamentação teórica, a metodologia e os resultados do estudo, bem como os achados e implicações do trabalho para a área.

\section{O MÉTODO DA ANÁLISE BIBLIOMÉTRICA}

A bibliometria é um conjunto de métodos de pesquisa em constante evolução, desenvolvido pela Biblioteconomia e pelas Ciências da Informação, que utiliza análises quantitativa, estatística e de visualização de dados não só para mapear a estrutura do conhecimento de um campo científico, mas também como uma ferramenta primária para a análise do comportamento dos pesquisadores em suas decisões na construção desse conhecimento (Vanti, 2002). Segundo autores da área (e.g. Wormell, 1998; Vanti, 2002), são cinco os principais tipos de metodologia utilizados pela bibliometria: análise de citações, análise de co-citação, agrupamento bibliográfico, co-word analysis, e "webometria". O presente trabalho enfoca e utiliza a primeira dessas metodologias (análise de citações) e, por esse motivo, deter-se-á especificamente nesse tipo de estudo, em suas origens, potencialidades, aplicações e limitações.

\section{Origens do uso de citações para análise de publicações científicas}

O estudo de citações, apesar de pouco difundido no campo da Administração no Brasil, não é tão recente quanto possa parecer na história da ciência. O primeiro índice de citações surgiu em 1873, nos Estados Unidos: o Shepard's ${ }^{\circledR}$ Citations (Weinstock, 1971). Os primeiros índices foram construídos com base em palavras-chave, termos ou frases que apareciam nos abstracts e títulos dos papers e estavam sujeitos à subjetividade, tanto por parte de quem inseria as informações no banco de dados quanto de quem procurava um determinado assunto ou tema. A partir dessa carência, na metade da década de 1950, Eugene Garfield sugeriu a criação de um sistema de citações que "avaliasse a relevância de um trabalho e seu impacto na literatura e no pensamento do período" (Garfield, 1955, p. 108). Em 1961, Garfield criou então o primeiro índice de citações em genética (Genetics Citation Index) e estabeleceu o Science Citation Index ${ }^{\circledR}$ (Garfield, 1979). Em 1973, criou o primeiro índice de citações em Ciências Sociais e, em 1978, um índice semelhante para Artes e Humanidades.

\section{0 que podem indicar as citações na pesquisa científica?}

A principal função das citações é fornecer ao leitor referências importantes sobre o campo de estudo em questão e a contribuição de autores predecessores para o trabalho atual. As citações simbolizam a origem ou fundamento dos conceitos e idéias que o autor discute em seu texto. Essas associações conceituais foram descritas por Merton (1983) como um reconhecimento formal de "débito intelectual" com os autores que trataram do tema anteriormente. De acordo com Vergara e Carvalho Jr. (1995, p. 170), as referências bibliográficas utilizadas por um autor são, além de suporte de argumentação, representação de suas "preocupações, preferências, suposições e metodologias", e evidenciam o quanto aquele autor atribui de importância à determinada produção científica de um determinado país, instituição, etc.

Kostoff (1998) afirma que quanto menor um trabalho científico maior a chance de ser lido em sua totalidade, uma vez que muitos cientistas não podem se dar ao luxo de passar grande quantidade de tempo procurando extrair algo de útil de um único trabalho. Nesse contexto, as citações funcionam como uma "referência condensada" a uma base de informações muito maior, e aqueles que tiverem interesse em acessá-la podem fazê-lo voltando aos originais em que o autor se baseou.

Outro papel exercido pela análise das citações é o de "ligação entre as diversas influências intelectuais" que influenciam um pesquisador ou área específica do conhecimento. Ou seja, ao analisar o percurso dessas ligações, é possível verificar a linha de pensamento seguida 
ou o paradigma utilizado pelos autores na construção de seu raciocínio apenas pela observação dos trabalhos, autores e veículos mais citados na pesquisa. Além desses fatores, é importante considerar também o impacto e os benefícios gerados por determinada pesquisa científica. A análise das citações permite, nesse caso, verificar o fluxo documentado e a evolução de uma determinada pesquisa ao longo do tempo, e pode servir, portanto, como fonte para se avaliar ou medir o impacto - direto e indireto - de uma pesquisa em particular, de um grupo ou instituição de pesquisadores, ou ainda de veículos de divulgação científica (Fujigaki, 1998).

\section{Utilizando análise bibliométrica na análise de produção científica}

A utilização dos Índices de Citações tornou-se uma prática comum, principalmente nos Estados Unidos, servindo como fonte para remuneração dos pesquisadores de diversas áreas. Periódicos totalmente voltados para a publicação do impacto de outros periódicos ou de pesquisas ganham cada vez mais popularidade, como é o caso do Journal of the American Society for Information Science. No mundo são diversos os exemplos de estudos de citações nas mais diferentes áreas, como, por exemplo, em Física, Química, Botânica, Economia e, menos freqüentemente, em Administração (Strehl e Santos, 2002; Bignetti e Paiva, 2002).

Embora potencialmente útil e rica, a análise de citações na pesquisa científica não é desprovida de crítica. Muitos autores (Macroberts, 1996; Kostoff, 1998; Carter, 1974; Meadows, 1974; Chandy e Williams, 1994) têm apontado suas limitações e os perigos de se basearem excessivamente em tais análises - o excesso de valor dado às "quantidades", em detrimento de uma saudável valorização dos aspectos qualitativos - para mapear campos de conhecimento. Nesse trabalho, não se desconhecem nem se desconsideram essas limitações, mas se faz uso da metodologia como uma ferramenta a mais - em meio a outras, usadas em outros estudos (e que os próprios autores também já utilizaram) no esforço de compreender o mosaico da produção acadêmica em Estudos Organizacionais no Brasil.

\section{METODOLOGIA}

\section{Amostra}

A base de dados enfocada neste artigo é densamente povoada; contém todas as citações feitas em RH nos Enanpads do período de 1991 a 2000. A escolha do período e do veículo Anais do Enanpad foi feita para manter consistên- cia e comparabilidade com estudos anteriores (Caldas et al., 2002; Vieira, 1998, 1999, 2000; Perin et al., 2000; Botelho e Macera, 2001; Hoppen et al., 1998; Bignetti e Paiva, 1997; Keinert, 2000). No período em questão, foram identificados 290 trabalhos, representando, no total, 5.814 citações, envolvendo 342 autores de 51 instituições. A forma de tratamento dessa base é descrita a seguir.

\section{Procedimentos}

$\mathrm{Na}$ pesquisa que deu origem a este artigo foi utilizada a análise das citações para observar as inter-relações de conhecimento na área de Recursos Humanos com base nos artigos que compõem a amostra deste estudo. O período de 1991 a 2000 foi escolhido por se tratar dos últimos dez anos de publicação da área de RH antes da separação da área de comportamento organizacional no Enanpad, que, como evidenciaram Tonelli et al. (2003), representava 50\% dos temas tratados na área, portanto, sem dúvida, uma contribuição importante à base de autores referidos.

O primeiro passo da tarefa de análise das inter-relações foi a tabulação de todos os artigos publicados no período mencionado, a partir da mesma base de dados utilizada em estudo anterior por Caldas et al. (2002). Foram tabulados autores, instituições declaradas de autoria e citações feitas - nomes dos autores citados, tipo de obra (livro, artigo ou outros), e se a origem dos autores da citação era nacional ou estrangeira.

Em seguida, os autores dos artigos foram categorizados em "autores com produção acadêmica anterior ao ano de publicação" e "sem produção acadêmica anterior". Esse passo se fez essencial para se analisar com mais justiça, e de forma mais relativizada, a questão de autocitações. Sem uma análise desse tipo, que leva em conta o curriculum dos autores, uma contagem simples de autocitações poderia camuflar muitas distorções.

Por exemplo, autores iniciantes (nos Enanpads, como se sabe, é onde mestrandos e doutorandos tipicamente conseguem suas primeiras publicações acadêmicas passíveis de citação) contariam zero em autocitação pelo simples fato de que não teriam produção anterior que pudessem citar. Então, para fazer essa categorização adicional, foi analisado o currículo Lattes de cada autor da amostra e, na ausência deste, feita uma busca em bibliotecas, nas livrarias e na internet para verificar se havia produção anterior divulgada. Assim, dos 290 artigos que compõem nossa amostra, 158 eram de autores com alguma produção anterior.

A contagem de autocitações é necessária uma vez que a metodologia da área, internacionalmente aceita e praticada (Garfield, 1979), indica que as citações a determinado 
autor a serem consideradas para efeitos de classificação ou ordenamento são apenas aquelas não feitas por ele próprio, uma vez que é o próprio autor que controla essa variável. Foram então contados os autores citados usandose dois critérios alternativos. No primeiro critério foi feita uma ponderação da base de autores citados; dessa forma, para uma obra com dois autores, cada um recebeu o equivalente a meia citação (Chandy e Williams, 1994). No segundo critério foi feita uma contagem simples, ou seja, independentemente do número de autores da obra citada. Assim, para a mesma obra com dois autores, foi atribuída uma citação ao primeiro e outra ao segundo (seguindo o padrão do Citation Index - Garfield, 1979).

No momento seguinte foram identificadas as instituições de origem dos autores citados, da mesma forma como foi feita a categorização da produção anterior. Para análise da instituição de origem da citação também foram adotados dois procedimentos, de acordo com os dois critérios alternativos testados neste estudo: no primeiro, a instituição foi ponderada da mesma forma que os autores; na segunda, foi atribuída uma instituição principal à obra citada pela preponderância de autores de determinada instituição. Ou seja, se uma obra citada apresenta dois autores da universidade " $x$ " e um da universidade "y", a instituição preponderante é a universidade " $x$ ".

Das 5.814 obras citadas e que compuseram nossa amostra, apenas para 60 não foi possível definir a instituição preponderante dessa maneira, pois eram casos de dois autores de instituições diferentes. Nessas situações, foi adotada a instituição do primeiro autor como preponderante. Da mesma forma que para autocitações, foi verificada e tabulada a ocorrência de citação à própria instituição, isto é, se a obra citada tinha algum autor com a mesma instituição de origem do autor do artigo. Esse índice é fundamental para se compreenderem as relações entre os autores da mesma instituição.

As conclusões parciais de cada uma das análises acima descritas foram complementadas com a análise qualitativa dos artigos, usando-se, para tanto, a base disponível do trabalho de Caldas et al. (2002). Os resultados a seguir derivam do cruzamento de todos esses dados e análises, seguindo os procedimentos acima, conforme veremos na subseção seguinte.

\section{RESULTADOS E DISCUSSÃO}

Nesta seção, os principais resultados do estudo serão resumidos e simultaneamente discutidos. A escolha pela discussão paralela à apresentação dos resultados deu-se em função da densidade dos dados, e pelo favorecimento de tal opção à fluidez do texto.

A análise da demografia da amostra em si é o primeiro ponto de discussão. Em relação ao grupo total de citações, chama a atenção o fato de que quase $63 \%$ do total de citações no período são feitas a autores estrangeiros. Esse alto índice de referência a obras e autores não brasileiros é consistente com estudos anteriores (Vergara, 1995, 1996, 2000; Bignetti e Paiva, 2002), e reforça a preocupação corrente com um campo de estudos (e em administração como um todo) talvez excessivamente "importado".

Outro exemplo da riqueza dos dados descritivos é o fato de revelarem que cerca de $12 \%$ do total de citações têm como fonte revistas, jornais e fontes semelhantes, em geral sem autor específico, e via de regra não acadêmicas; mostram ainda que quase $7 \%$ do total de citações são feitas a autores não acadêmicos (executivos e empresários, "gurus", autores profissionais de livros-texto etc.). Esse quadro, preocupante, já foi apontado por outros autores (Wood Jr. e Paula, 2002), que enfocaram a propensão da academia e da práxis brasileira em Administração em apoiar-se no gerencialismo de pouca ou nenhuma base científica. Ao menos é possível reconhecer que esse tipo de fonte é consistente com o uso de revistas como a Exame, HSM e Você S.A., que parecem embasar muitos de nossos autores.

Somados esses grupos acima, que muito dificilmente seriam aceitos como referência em trabalho científico em qualquer campo ou lugar atualmente, somente $29 \%$ do total de citações feitas no período são de fontes, autores e periódicos acadêmicos e nacionais.

A análise em maior profundidade da demografia de origem dessas citações revela muito da diversidade de referência, ou de sua falta, na área. Das citações acadêmicas nacionais, quase $47 \%$ derivam de autores de três instituições, e 56\% de apenas cinco programas de pós-graduação, mostrando a falta de diversidade na fonte de conhecimento do campo já denunciada por outros autores (Vieira, 1998, 2003; Vergara, 1995, 1996, 2000; Tonelli et al., 2003).

\section{Tipos de citação e veículos mais citados}

A maioria dos trabalhos citados é de livros (43\% das citações), seguidos de artigos em periódicos (24\%), artigos em livros (9\%) e artigos em congressos (5\%). Quando são focalizados apenas os artigos em periódicos e congressos, constata-se que as citações estão pulverizadas em muitos veículos distintos. Os mais representativos destes não têm mais do que 3\% das citações, no caso da RAE e dos periódicos nacionais, e não mais do que $1,5 \%$, no caso dos periódicos estrangeiros. 
Um dos desafios dessa dispersão é que, na medida em que o acesso a uma base tão pulverizada ainda é difícil e precário atualmente, muitos autores acabam não tendo acesso à obra original para analisar o contexto e/ou detalhes do trabalho. Essa falta de acesso, aliada à citada inclinação à literatura gerencialista (Wood Jr. e Paula, 2002), pode acabar elevando o número de "apuds" (leitura por meio de revisões de outrem, e não no original), enfraquecendo ainda mais a base de referências da área, e deixando dúvidas sobre a validação de determinados conceitos e teorias construídas com base nesse tipo de fonte.

Isolando a citação a obras em veículos nacionais, fica evidente o forte impacto da RAE (2,6\% do total de citações) e do próprio Enanpad (2,3\%), seguidos da RAUSP $(1,72 \%)$. No entanto, a análise da origem dessas citações nos mostra que alguns desses veículos são mais prestigiados por algumas instituições, enquanto outros chegam a ser ignorados por muitos autores ou programas (Tabela 1).

A UFMG, por exemplo, tem alta incidência relativa de citação a periódicos e congressos nacionais, porém, ao contrário da amostra geral, privilegia mais as publicações do Enanpad (48 citações) do que as da RAE (38) ou de qualquer outro periódico. A UFRGS segue o padrão geral em relação a artigos do Enanpad (20) e da RAE (22), mas privilegia mais fortemente citações da RAUSP do que a média das instituições (citações dessa fonte são em número duas vezes maior do que a média). A RAUSP mostrou-se pouco citada pela UFBA (1), enquanto a FEA-USP, a FGV-EAESP, a PUC-RJ e a UFPE citaram menos o Enanpad do que a média dos programas.

\section{Autores e instituições mais citados}

A Tabela 2 mostra um mapa dos autores mais citados pela área no período. Como discutido anteriormente, as classificações foram feitas seguindo-se os dois critérios, a saber, com e sem ponderação de múltipla autoria, gerando duas séries de classificação. A Tabela 2 mostra ainda, dentro de cada série (com e sem ponderação), as classificações antes e depois de feito o ajuste para autocitação - ou seja, antes e depois de eliminar da contagem de citações as autocitações, como é internacionalmente aceito e recomendado em estudos desse tipo (Chandy e Williams, 1994); as classificações depois do ajuste para as citações feitas por autores da própria instituição; e as classificações com e sem citações estrangeiras.

Apesar de rica, a Tabela 2 pode ser de difícil interpretação. Essencialmente, o que se mostra são os mais variados tipos de escalonamento dos autores mais citados na amostra. Na primeira metade (esquerda) da tabela é usado o critério de ponderações e reduções por múltipla autoria, sendo apresentadas variações no escalonamento quando se toma a base com e sem autocitações, e também com e sem citações estrangeiras. Na segunda metade (direita) da tabela, as mesmas variações são feitas, mas para o escalonamento obtido sem ponderações (ou seja, contando-se uma citação inteira para cada referência ao autor, independentemente de ser ou não um trabalho em parceria).

A nota positiva que esta análise traz é que, usando qualquer critério ou independentemente de qualquer ajuste, a professora Maria Tereza Fleury (da FEA-USP) é a autora mais citada na área no período analisado, revelando o significativo impacto e a durabilidade de seu tra-

Tabela 1 - Citações aos principais veículos de administração nacionais na amostra por instituição citante.

\begin{tabular}{|c|c|c|c|c|c|c|c|}
\hline \multirow[b]{2}{*}{ INSTITUIÇÃO DO AUTOR } & \multicolumn{5}{|c|}{$\mathrm{N}^{0}$ DE CIT. AOS PRINCIPAIS VEÍCULOS NACIONAIS } & \multirow[b]{2}{*}{ \% TOTAL CIT. } & \multirow[b]{2}{*}{$\%$ CIT. NAC. } \\
\hline & ANPAD & RAC & RAE & RAP & RAUSP & & \\
\hline UFMG & 48 & 2 & 38 & 11 & 19 & $7 \%$ & $18 \%$ \\
\hline UFRGS & 20 & 1 & 22 & 2 & 19 & $9 \%$ & $18 \%$ \\
\hline UFSC & 3 & 0 & 8 & 0 & 10 & $10 \%$ & $21 \%$ \\
\hline UFRN & 7 & 0 & 16 & 1 & 2 & $13 \%$ & $27 \%$ \\
\hline USP & 3 & 0 & 9 & 0 & 11 & $4 \%$ & $12 \%$ \\
\hline EAESP & 2 & 0 & 14 & 0 & 2 & $7 \%$ & $35 \%$ \\
\hline UFPB & 5 & 1 & 7 & 0 & 3 & $8 \%$ & $19 \%$ \\
\hline PUC-RJ & 1 & 0 & 9 & 4 & 2 & $13 \%$ & $31 \%$ \\
\hline UFPE & 1 & 0 & 6 & 0 & 4 & $4 \%$ & $13 \%$ \\
\hline UFBA & 6 & 1 & 4 & 1 & 1 & $4 \%$ & $13 \%$ \\
\hline Total & 96 & 5 & 133 & 19 & 73 & $7 \%$ & $18 \%$ \\
\hline
\end{tabular}


balho e pesquisa ao longo do tempo. Ainda na dimensão positiva, muitos dos autores mais citados mantêm suas classificações (ou mostram variação muito pequena) após serem expurgadas autocitações ou feitas ponderações e reduções por múltipla autoria. De fato, a diferença entre um e outro escalonamento (com e sem autocitação) varia conforme o padrão de citação do autor: enquanto $40 \%$ das posições se mantêm iguais ou melhoram quando se descontam as autocitações, em $60 \%$ dos casos a posição relativa caiu quando foram retiradas as auto-referências.

Nesse segundo sentido, alguns autores sofrem grande variação na classificação em função de trabalharem habitualmente com múltipla autoria. Analisando-se a produção desses autores, e de outros com perfil semelhante, é possível perceber que o critério de ponderação, embora lógico e razoável, pode contra-incentivar práticas saudáveis de cooperação e de linhas de pesquisa interinstitucio- nais, dos quais nosso campo tanto parece precisar. Por outro lado, autores que defendem a aplicação do critério de ponderação contra-argumentam que, para cada bemintencionado e positivo autor efetivamente colaborativo, há outros tantos que, por terem tão-somente revisto ou opinado sobre trabalho alheio (muitas vezes, de alunos), demandam co-autoria e, a partir daí, inflacionam sua base de publicações (e futuramente de citações). Já que é difícil fazer as devidas separações, e ambas as práticas não são incomuns na área, parece ser fundamental que o campo debata e defina princípios tanto éticos e de comportamento para autoria e citação quanto de classificação para estudos dessa natureza. É útil observar que, como previam alguns críticos ao método, a maioria dos autores mais bem classificados na amostra tem de fato no campo história mais longa que os demais. Isso reforça a necessidade de o campo discutir, sobre os critérios desse tipo de classifica-

Tabela 2 - Autores mais citados.

\begin{tabular}{|c|c|c|c|c|c|c|c|c|c|c|c|c|c|c|c|c|}
\hline \multirow[b]{3}{*}{ AUTOR CITADO } & \multicolumn{8}{|c|}{ BASE PONDERADA } & \multicolumn{8}{|c|}{ BASE SEM PONDERAÇÃO } \\
\hline & \multirow[b]{2}{*}{$\begin{array}{c}\text { TOTAL } \\
\text { CIT. }\end{array}$} & \multicolumn{7}{|c|}{ RANKING DAS CITAÇÕES } & \multirow[b]{2}{*}{$\begin{array}{c}\text { TOTAL } \\
\text { CIT. }\end{array}$} & \multicolumn{7}{|c|}{ RANKING DAS CITAÇÕES } \\
\hline & & $\begin{array}{c}\text { SEM } \\
\text { AUTO- } \\
\text { CIT. }\end{array}$ & $\begin{array}{l}T \\
1 \\
1 \\
1\end{array}$ & $\begin{array}{c}\text { SEM } \\
\text { CIT. } \\
\text { INST. }\end{array}$ & $\begin{array}{l}1 \\
\text { I } \\
\text { I } \\
\text { I }\end{array}$ & $\begin{array}{l}\text { TODAS } \\
\text { CIT. }\end{array}$ & $\begin{array}{l}\text { I } \\
\text { I } \\
\text { I }\end{array}$ & $\begin{array}{l}\text { ClT. } \\
\text { NAC. }\end{array}$ & & $\begin{array}{c}\text { SEM } \\
\text { AUTO- } \\
\text { CIT. }\end{array}$ & $\begin{array}{l}T \\
\text { I } \\
\text { I } \\
\text { I }\end{array}$ & $\begin{array}{c}\text { SEM } \\
\text { CIT. } \\
\text { INST. }\end{array}$ & $\begin{array}{l}1 \\
1 \\
1 \\
1\end{array}$ & $\begin{array}{l}\text { TODAS } \\
\text { CIT. }\end{array}$ & $\begin{array}{l}T \\
1 \\
1 \\
I\end{array}$ & $\begin{array}{l}\text { ClT. } \\
\text { NAC. }\end{array}$ \\
\hline FLEURY, M. & 55,67 & $1^{0}$ & 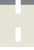 & $1^{0}$ & ta & $1^{0}$ & & $1^{0}$ & 70 & $1^{0}$ & I & $1^{0}$ & & $1^{0}$ & I & $1^{0}$ \\
\hline CHIAVENATO, I. & 30,00 & $2^{0}$ & $\mathrm{~T}$ & $2^{\circ}$ & T & $6^{0}$ & & $4^{0}$ & 30 & $4^{0}$ & T & $3^{\circ}$ & & $11^{\circ}$ & & $7^{0}$ \\
\hline FISCHER, R. M. & 30,00 & $2^{\circ}$ & 1 & $10^{\circ}$ & 1 & $5^{0}$ & & $3^{\circ}$ & 43 & $2^{0}$ & 1 & $7^{0}$ & 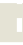 & $4^{0}$ & 1 & $3^{\circ}$ \\
\hline BERGAMINI, C. & 26,50 & $3^{\circ}$ & th & $5^{0}$ & trat & $9^{\circ}$ & & $5^{0}$ & 28 & $6^{0}$ & r & $6^{0}$ & & $12^{\circ}$ & & $8^{\circ}$ \\
\hline BASTOS, A. & 24,17 & $4^{0}$ & I & $6^{0}$ & I & $12^{\circ}$ & & $8^{\circ}$ & 28 & $6^{0}$ & I & $5^{0}$ & 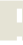 & $11^{\circ}$ & & $7^{0}$ \\
\hline FERNANDES, E. & 22,50 & $5^{0}$ & 1 & $3^{0}$ & I & $10^{\circ}$ & & $7^{0}$ & 29 & $5^{0}$ & I & $4^{0}$ & & $9^{\circ}$ & & $5^{0}$ \\
\hline MOTTA, P. & 22,50 & $5^{0}$ & 1 & $4^{0}$ & 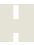 & $15^{\circ}$ & & $11^{\circ}$ & 22 & $8^{\circ}$ & 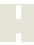 & $7^{0}$ & & $16^{\circ}$ & & $10^{\circ}$ \\
\hline ALBUQUERQUE, L. & 21,50 & $6^{0}$ & 1 & $7^{0}$ & 1 & $13^{\circ}$ & & $9^{\circ}$ & 22 & $8^{\circ}$ & 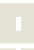 & $8^{\circ}$ & 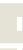 & $14^{\circ}$ & & $9^{\circ}$ \\
\hline MORAES, L. & 20,91 & $7^{0}$ & 1 & $26^{\circ}$ & 1 & $14^{0}$ & & $10^{\circ}$ & 26 & $7^{0}$ & 1 & $13^{\circ}$ & & $6^{0}$ & & $4^{0}$ \\
\hline FLEURY, A. & 20,75 & $8^{\circ}$ & T & $14^{\circ}$ & T & $16^{\circ}$ & & $12^{\circ}$ & 29 & $5^{0}$ & T & $9^{\circ}$ & & $9^{\circ}$ & & $6^{0}$ \\
\hline BORGES-ANDRADE, J. & 20,22 & $9^{\circ}$ & I & $9^{\circ}$ & 1 & $8^{\circ}$ & 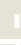 & $6^{0}$ & 35 & $3^{\circ}$ & I & $2^{\circ}$ & 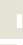 & $2^{\circ}$ & 1 & $2^{0}$ \\
\hline LEITE, M. & 18,50 & $10^{\circ}$ & 1 & $8^{0}$ & 1 & $23^{\circ}$ & & $13^{\circ}$ & 20 & $10^{\circ}$ & 1 & $8^{\circ}$ & & $18^{\circ}$ & & $12^{\circ}$ \\
\hline MELO, M. & 17,50 & $11^{\circ}$ & 1 & $32^{\circ}$ & 1 & $4^{0}$ & & $2^{\circ}$ & 16 & $12^{\circ}$ & 7 & $19^{\circ}$ & 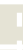 & $10^{\circ}$ & & $6^{0}$ \\
\hline MOTTA, F. & 16,08 & $12^{\circ}$ & 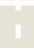 & $12^{\circ}$ & t & $27^{\circ}$ & & $15^{\circ}$ & 21 & $9^{\circ}$ & 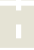 & $10^{\circ}$ & & $17^{\circ}$ & & $11^{\circ}$ \\
\hline SALERNO, M. & 15,25 & $13^{\circ}$ & 1 & $17^{\circ}$ & 1 & $31^{\circ}$ & & $18^{\circ}$ & 17 & $11^{\circ}$ & 1 & $13^{\circ}$ & & $21^{\circ}$ & & $13^{\circ}$ \\
\hline LODI , J.B. & 15,00 & $14^{\circ}$ & 1 & $11^{0}$ & 1 & $33^{\circ}$ & 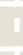 & $19^{\circ}$ & 15 & $13^{\circ}$ & 1 & $11^{\circ}$ & 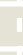 & $23^{\circ}$ & 1 & $15^{0}$ \\
\hline CAMPOS, V. & 15,00 & $14^{\circ}$ & 1 & $15^{\circ}$ & 1 & $32^{\circ}$ & & $19^{\circ}$ & 15 & $13^{\circ}$ & 1 & $13^{\circ}$ & & $23^{\circ}$ & & $15^{0}$ \\
\hline DA MATTA, R. & 13,00 & $15^{\circ}$ & $\pi$ & $13^{\circ}$ & I & $36^{\circ}$ & & $19^{\circ}$ & 13 & $15^{\circ}$ & $\pi$ & $12^{\circ}$ & & $25^{\circ}$ & & $16^{\circ}$ \\
\hline KILIMNIK, Z. & 12,10 & $16^{\circ}$ & I & $45^{\circ}$ & I & $29^{\circ}$ & 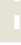 & $16^{\circ}$ & 16 & $12^{\circ}$ & I & $18^{\circ}$ & 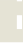 & $14^{\circ}$ & 1 & $9^{\circ}$ \\
\hline RODRIGUES, M. B. & 12,08 & $17^{\circ}$ & 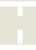 & $19^{\circ}$ & 1 & $39^{\circ}$ & & $21^{\circ}$ & 15 & $13^{\circ}$ & 1 & $14^{\circ}$ & & $23^{\circ}$ & & $15^{0}$ \\
\hline SIQUEIRA, M. & 11,92 & $19^{\circ}$ & 1 & $37^{\circ}$ & 1 & $26^{\circ}$ & & $14^{\circ}$ & 9 & $19^{\circ}$ & 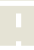 & $20^{\circ}$ & & $18^{\circ}$ & & $12^{\circ}$ \\
\hline COUTO, H. & 11,33 & $21^{\circ}$ & 1 & $59^{\circ}$ & 1 & $30^{\circ}$ & & $17^{\circ}$ & 9 & $19^{\circ}$ & 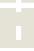 & $23^{\circ}$ & 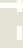 & $22^{\circ}$ & 1 & $14^{\circ}$ \\
\hline ROESCH, S. & 11,00 & $22^{\circ}$ & 1 & $44^{\circ}$ & 1 & $37^{\circ}$ & & $20^{\circ}$ & 13 & $15^{\circ}$ & T & $22^{\circ}$ & & $22^{\circ}$ & & $14^{\circ}$ \\
\hline
\end{tabular}


ção, se deve incluir ou não um ajuste ou ponderação em relação à idade da produção acadêmica do autor, visando a mensuração mais precisa do impacto efetivo da sua produção científica média.

A nota negativa trazida por esta análise da classificação dos autores mais citados pode ser desdobrada em dois registros. Primeiro, a inclusão questionável, em alta posição na classificação, de autores profissionais de livros-texto, e não pesquisadores engajados em investigação científica. Isso indica que muitos de nossos autores usam base de segunda mão, via "apuds". É mais um registro da já comentada base frágil da nossa área, e que sem dúvida deve-se procurar superar na produção científica do campo. O segundo registro negativo é a significativa alteração (para baixo) da classificação de alguns autores quando se faz o ajuste para autocitação. Em outras palavras, como mais adiante será abordado no dado agregado, a preocupação com a existência de abusiva autocitação em nosso campo não parece descabida, ao contrário do que previa Garfield (1979) para o contexto norte-americano, pois nossos periódicos e congressos não parecem ter ativado os mecanismos para coibir e se proteger desse tipo de excesso.

Com exceção dessa classificação de autores mais citados, e por respeito à privacidade dos profissionais envolvidos, os demais dados apresentados a seguir serão agregados por instituição, não enfocando resultados individuais. Quando analisada a classificação das instituições mais citadas no período (Tabela 3), nota-se uma preocupante ausência de diversidade que acompanha o que estudos anteriores (Vieira, 1998, 2003; Vergara, 1995, 1996, 2000; Tonelli et al., 2003) apontam para o caso de autoria: cerca de $47 \%$ das citações nacionais acadêmicas da área no período é feita a autores que provêm de três instituições (USP, UFMG, UFRGS), e cerca de 55\% provêm de apenas cinco programas.

Uma importante constatação desta pesquisa é que nem todas as instituições que mais produziram no período de acordo com pesquisas anteriores (Caldas et al., 2002) foram as mais citadas. Obras de pesquisadores da

Tabela 3 - Instituições nacionais mais citadas.

\begin{tabular}{|c|c|c|c|c|c|c|c|c|c|c|}
\hline \multirow[b]{3}{*}{ INSTITUIÇÃO CITADA } & \multicolumn{5}{|c|}{ BASE PONDERADA } & \multicolumn{5}{|c|}{ BASE SEM PONDERAÇÃO } \\
\hline & \multirow[b]{2}{*}{$\begin{array}{l}\text { TOTAL } \\
\text { CIT. }\end{array}$} & \multicolumn{4}{|c|}{ RANKING DAS CITAÇÕES } & \multirow[b]{2}{*}{$\begin{array}{c}\text { TOTAL } \\
\text { CIT. }\end{array}$} & \multicolumn{4}{|c|}{ RANKING DAS CITAÇÕES } \\
\hline & & $\begin{array}{r}\text { SEM } \\
\text { AUTO- } \\
\text { CIT. }\end{array}$ & ! & $\begin{array}{r}\text { SEM } \\
\text { CIT. } \\
\text { INST. }\end{array}$ & $\begin{array}{c}\text { CIT. } \\
\text { NAC. }\end{array}$ & & $\begin{array}{c}\text { SEM } \\
\text { AUTO- } \\
\text { CIT. }\end{array}$ & $\begin{array}{c}\text { SEM } \\
\text { CIT. } \\
\text { INST. }\end{array}$ & $\begin{array}{l}i \\
i\end{array}$ & $\begin{array}{l}\text { CIT. } \\
\text { NAC }\end{array}$ \\
\hline USP & 351,33 & $1^{0}$ & & $1^{0}$ & $1^{0}$ & 460 & $1^{0}$ & $1^{0}$ & & $1^{\circ}$ \\
\hline UFMG & 261,52 & $2^{0}$ & & $4^{0}$ & $2^{\circ}$ & 385 & $2^{0}$ & $4^{0}$ & & $2^{\circ}$ \\
\hline UFRGS & 184,58 & $3^{0}$ & 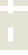 & $3^{\circ}$ & $3^{\circ}$ & 266 & $3^{\circ}$ & $3^{\circ}$ & & $3^{\circ}$ \\
\hline FGV-EAESP & 153,17 & $4^{\circ}$ & & $2^{\circ}$ & $4^{0}$ & 202 & $4^{\circ}$ & $2^{\circ}$ & & $4^{\circ}$ \\
\hline UNB & 86,98 & $5^{0}$ & 1 & $6^{\circ}$ & $5^{0}$ & 185 & $6^{0}$ & $5^{0}$ & & $5^{\circ}$ \\
\hline UNICAMP & 80,67 & $6^{0}$ & & $5^{\circ}$ & $6^{0}$ & 91 & $5^{0}$ & $6^{0}$ & & $7^{\circ}$ \\
\hline UFBA & 72,58 & $7^{0}$ & & $7^{0}$ & $7^{0}$ & 106 & $7^{0}$ & $7^{0}$ & & $6^{\circ}$ \\
\hline PUC-RJ & 46,33 & $8^{\circ}$ & & $8^{\circ}$ & $9^{\circ}$ & 56 & $8^{\circ}$ & $8^{\circ}$ & & $9^{\circ}$ \\
\hline FGV-EBAPE & 45,67 & $9^{\circ}$ & & $9^{\circ}$ & $8^{\circ}$ & 57 & $9^{\circ}$ & $9^{\circ}$ & & $8^{\circ}$ \\
\hline UFSC & 40,00 & $10^{\circ}$ & & $13^{\circ}$ & $10^{\circ}$ & 50 & $10^{\circ}$ & $11^{\circ}$ & & $10^{\circ}$ \\
\hline UFPB & 35,83 & $11^{\circ}$ & & $11^{\circ}$ & $11^{\circ}$ & 45 & $11^{\circ}$ & $16^{\circ}$ & & $11^{\circ}$ \\
\hline UFRN & 30,83 & $12^{\circ}$ & & $18^{\circ}$ & $12^{\circ}$ & 39 & $13^{\circ}$ & $21^{\circ}$ & & $12^{\circ}$ \\
\hline UFRJ & 30,50 & $13^{\circ}$ & I & $10^{\circ}$ & $13^{\circ}$ & 36 & $12^{\circ}$ & $10^{\circ}$ & & $13^{\circ}$ \\
\hline UFPE & 29,00 & $14^{\circ}$ & & $13^{\circ}$ & $14^{\circ}$ & 36 & $13^{\circ}$ & $13^{\circ}$ & & $13^{\circ}$ \\
\hline UNIFOR & 20,25 & $15^{\circ}$ & & $14^{\circ}$ & $15^{\circ}$ & 26 & $14^{\circ}$ & $14^{\circ}$ & & $14^{\circ}$ \\
\hline PUC-SP & 19,00 & $16^{\circ}$ & 1 & $12^{\circ}$ & $16^{\circ}$ & 22 & $14^{\circ}$ & $12^{\circ}$ & & $15^{\circ}$ \\
\hline UFES & 13,50 & $17^{\circ}$ & & $17^{\circ}$ & $17^{\circ}$ & 16 & $15^{\circ}$ & $15^{\circ}$ & & $17^{\circ}$ \\
\hline UNESP & 13,33 & $18^{\circ}$ & & $15^{\circ}$ & $18^{\circ}$ & 20 & $16^{\circ}$ & $13^{\circ}$ & & $16^{\circ}$ \\
\hline UFF & 12,50 & $19^{\circ}$ & & $16^{\circ}$ & $19^{\circ}$ & 13 & $17^{\circ}$ & $17^{\circ}$ & & $18^{\circ}$ \\
\hline UFPR & 11,00 & $20^{\circ}$ & & $19^{\circ}$ & $20^{\circ}$ & 12 & $18^{\circ}$ & $18^{\circ}$ & & $19^{\circ}$ \\
\hline
\end{tabular}


Unicamp e da UnB, por exemplo, tiveram forte impacto na produção da área no período, mesmo quando não foram tão representativas na escala de autoria. A alta importância da Unicamp, que não possui curso de Administração, parece dever-se à significativa expressão dos pesquisadores daquela instituição em temas como economia, sociologia do trabalho e saúde do trabalho. Parece ser importante que a área reveja e aprofunde os laços inter-instituições com universidades que, como essa, podem fortemente interagir com nossos autores.

\section{Olhando para fora ou para o próprio quintal}

A Tabela 4 mostra um interessante perfil do padrão de citação na amostra, relativo à excessiva participação de autoria estrangeira e de citação de obras da própria instituição.

No que tange à participação da referência estrangeira, os dados revelam que $63 \%$ do total de citações no período são feitas a autores estrangeiros. Esse alto índice de referência a obras e autores não brasileiros é consistente com estudos anteriores (Vieira, 1998, 2003; Vergara, 1995, 1996, 2000; Arkader, 2003), e reforça a preocupação corrente com um campo de estudos talvez excessivamente importado. É verdade que o fato de a produção acadêmica brasileira no campo ser relativamente recente e ainda incipiente, quando comparada à produção internacional, pode ajudar a justificar parte da citação estrangeira. No entanto, quando se contrastam esses índices com os elevados níveis de autocitação e de citação à própria instituição, parece impossível deixar de creditar boa parte dessa tendência de importação também a vieses dos pesquisadores.

Os dados aqui expostos mostram que há uma tendência em citar pouco a produção brasileira, com exceção daquela provinda da própria instituição do autor. De fato, quando analisada a distribuição desse padrão de citação por instituição, percebe-se que a base de citações está realmente muito concentrada. A maioria dos autores citados provém do exterior ou da própria instituição do autor. Isso revela uma falta de conhecimento, interesse ou qualificação do que é produzido nacionalmente.

Os casos da FGV-EAESP e da USP representam bem essa tendência: no primeiro caso, $79 \%$ da base citada é internacional e, dos autores nacionais, quase $50 \%$ são autores da própria instituição; no caso da USP, 68\% da base de autores citados são de autores internacionais, e $56 \%$ do restante são da própria instituição. Apesar de mais extremos, esses dois casos não são uma exceção na amostra. Obviamente, não se trata de criticar o excesso de referência à produção estrangeira por pura xenofobia. O cerne desse problema não é a mera ocorrência da citação a um autor ou obra estrangeiros, mas é o excesso de incidência, a escolha da referência meramente por ser estrangeira, e/ou a desvalorização da produção local unicamente por ser nacional (ou por não ser do próprio autor).

De fato, quando a presença estrangeira não é majoritária, prevalece a referência a obras da própria instituição. Na Tabela 5, isso pode ser visto no relacionamento entre as instituições (o quanto uma cita a outra). Sem exceção, excluída a citação estrangeira, a maioria das citações é feita a obras advindas da própria instituição do autor, confirmando a tabela anterior: USP (com 18\% do total das citações à própria instituição), UnB (com 17\%) e UFRGS (com 16\%) encabeçam essa tendência. Percebe-se que a recomendada construção de redes e maiores relações interinstitucionais na área (Fischer, 1993) é de fato necessária e premente.

Tabela 4 - Procedência das citações - \% do total de citações feitas no artigo - classificação por instituição de origem do autor.

\begin{tabular}{|c|c|c|c|}
\hline INST. DE ORIGEM DO AUTOR & $\%$ CIT. ESTRANGEIRAS & \% CIT. A PRÓPRIA INST. & $\%$ CIT. NACIONAIS A PRÓPRIA INST. \\
\hline EAESP & $79 \%$ & $10 \%$ & $49 \%$ \\
\hline USP & $68 \%$ & $18 \%$ & $56 \%$ \\
\hline UFBA & $66 \%$ & $7 \%$ & $22 \%$ \\
\hline UNB & $64 \%$ & $17 \%$ & $48 \%$ \\
\hline UFPE & $62 \%$ & $6 \%$ & $16 \%$ \\
\hline UFMG & $58 \%$ & $14 \%$ & $34 \%$ \\
\hline UFPB & $55 \%$ & $9 \%$ & $21 \%$ \\
\hline UFRGS & $54 \%$ & $16 \%$ & $34 \%$ \\
\hline UFSC & $53 \%$ & $11 \%$ & $24 \%$ \\
\hline UFRN & $52 \%$ & $12 \%$ & $26 \%$ \\
\hline EBAPE & $45 \%$ & $8 \%$ & $14 \%$ \\
\hline
\end{tabular}




\section{Incidência e padrões de autocitação}

Um dos resultados mais expressivos do estudo é o elevado índice de autocitação e como tal prática constitui um padrão razoavelmente consistente por instituição de origem do autor. Em certo grau, esse tipo de análise revela a ocorrência do "narcisismo acadêmico" médio na área, e a forma como esse tipo de padrão se reproduz no campo. Como mostra a Tabela 5, muitas das instituições mais citadas no período apresentam incidência significativa de autocitação. O interessante desse quadro é mostrar a incidência por artigo de autocitações, atenuando o argumento de que a autocitação se justificaria quando o autor cita um único estudo (tese, projeto de pesquisa, etc.) que origina o artigo.

Pelo levantamento, essa tendência de autocitação unitária não é prevalecente na amostra estudada, embora exista. Quando se agregam esses padrões de autocitação por instituição e não por autor, como é feito neste trabalho, autores com baixa autocitação por terem pouco que citar podem distorcer a incidência desse tipo de padrão para baixo. Por esse motivo, como mencionado na seção metodológica, levantou-se a produção anterior de todos os autores da amostra, buscando um a um a existência de produção acadêmica anterior. Com base nessa informação adicional, foram recalculados os índices de incidência de autocitação apenas para aqueles autores que tinham produção passível de autocitação no ano de publicação do trabalho (Tabela 6). Os dados são mais uma vez expressivos e denotam a significativa incidên- cia (ou seja, mais do que mera ocorrência unitária, múltipla ocorrência por artigo) de autocitação no período. Usando essa base, 70\% das instituições cujos autores tinham produção anterior apresentam artigos com pelo menos uma autocitação, e uma parte expressiva de autores da amostra tem elevada incidência de três, quatro ou até mais autocitações por artigo.

\section{Incidência e padrões de citação à própria instituição}

Muitos dos autores da amostra - e, no agregado, suas instituições - podiam não ter grande incidência de autocitação, mas privilegiavam citações à própria instituição, como vimos nas Tabelas 4 a 6 . No entanto, cabe aqui analisar a incidência desse padrão de citação à própria instituição. Em outras palavras, cabe discernir entre aqueles que citam obras da própria instituição uma única vez daqueles que o fazem múltiplas vezes por artigo. Se a análise de incidência de autocitação mensurava algo como o "narcisismo acadêmico", a análise de incidência de citações à própria instituição mensura algo semelhante ao "ufanismo" ou "bairrismo" acadêmico.

Muitas das instituições com alta incidência de autocitação por artigo também apresentam alta incidência de citações à própria instituição por publicação (Tabela 7). As mais altas incidências e algumas das classificações em autocitações se repetem ou chegam perto disso no que tange a citações da própria instituição. Essa semelhança tem uma certa coerência; afinal, quando os autores se

Tabela 5 - Relacionamento entre instituições - \% de referências a outras instituições.

\begin{tabular}{|c|c|c|c|c|c|c|c|c|c|c|c|c|}
\hline \multirow{2}{*}{$\begin{array}{l}\text { INSTITUIÇÃO DO } \\
\text { AUTOR DA CITAÇÃO }\end{array}$} & \multicolumn{12}{|c|}{ INSTITUIÇÃO DE ORIGEM DO AUTOR DO ARTIGO } \\
\hline & UFMG & UFRGS & USP & UFBA & EAESP & UFPE & UFSC & UFRN & UNB & UFPB & EBAPE & PUC-RJ \\
\hline EXTERIOR & $58 \%$ & $54 \%$ & $68 \%$ & $66 \%$ & $79 \%$ & $62 \%$ & $53 \%$ & $52 \%$ & $64 \%$ & $55 \%$ & $45 \%$ & $61 \%$ \\
\hline USP & $5 \%$ & $5 \%$ & $18 \%$ & $3 \%$ & $4 \%$ & $7 \%$ & $7 \%$ & $4 \%$ & $4 \%$ & $5 \%$ & $5 \%$ & $8 \%$ \\
\hline UFMG & $14 \%$ & $2 \%$ & $1 \%$ & $3 \%$ & $0 \%$ & $1 \%$ & $4 \%$ & $3 \%$ & $0 \%$ & $3 \%$ & $0 \%$ & $1 \%$ \\
\hline EAESP & $2 \%$ & $2 \%$ & $1 \%$ & $2 \%$ & $10 \%$ & $1 \%$ & $2 \%$ & $5 \%$ & $1 \%$ & $4 \%$ & $3 \%$ & $2 \%$ \\
\hline UFRGS & $2 \%$ & $16 \%$ & $0 \%$ & $2 \%$ & $0 \%$ & $3 \%$ & $5 \%$ & $5 \%$ & $1 \%$ & $1 \%$ & $2 \%$ & $1 \%$ \\
\hline UNB & $1 \%$ & $1 \%$ & $1 \%$ & $3 \%$ & $0 \%$ & $0 \%$ & $1 \%$ & $1 \%$ & $17 \%$ & $0 \%$ & $1 \%$ & $1 \%$ \\
\hline UNICAMP & $2 \%$ & $3 \%$ & $1 \%$ & $1 \%$ & $0 \%$ & $0 \%$ & $1 \%$ & $3 \%$ & $0 \%$ & $0 \%$ & $1 \%$ & $1 \%$ \\
\hline UFBA & $1 \%$ & $1 \%$ & $1 \%$ & $7 \%$ & $0 \%$ & $0 \%$ & $0 \%$ & $1 \%$ & $7 \%$ & $1 \%$ & $1 \%$ & $1 \%$ \\
\hline EBAPE & $1 \%$ & $0 \%$ & $0 \%$ & $1 \%$ & $0 \%$ & $0 \%$ & $0 \%$ & $1 \%$ & $0 \%$ & $1 \%$ & $8 \%$ & $3 \%$ \\
\hline PUC-RJ & $1 \%$ & $0 \%$ & $0 \%$ & $0 \%$ & $0 \%$ & $0 \%$ & $0 \%$ & $1 \%$ & $0 \%$ & $1 \%$ & $0 \%$ & $8 \%$ \\
\hline UFSC & $0 \%$ & $1 \%$ & $0 \%$ & $0 \%$ & $0 \%$ & $0 \%$ & $11 \%$ & $0 \%$ & $0 \%$ & $0 \%$ & $0 \%$ & $0 \%$ \\
\hline UFPB & $0 \%$ & $0 \%$ & $0 \%$ & $0 \%$ & $0 \%$ & $1 \%$ & $1 \%$ & $0 \%$ & $0 \%$ & $9 \%$ & $1 \%$ & $0 \%$ \\
\hline UFRN & $0 \%$ & $0 \%$ & $0 \%$ & $0 \%$ & $0 \%$ & $0 \%$ & $0 \%$ & $12 \%$ & $2 \%$ & $0 \%$ & $0 \%$ & $0 \%$ \\
\hline UFRJ & $0 \%$ & $1 \%$ & $1 \%$ & $0 \%$ & $0 \%$ & $0 \%$ & $0 \%$ & $1 \%$ & $1 \%$ & $0 \%$ & $0 \%$ & $2 \%$ \\
\hline UFPE & $0 \%$ & $0 \%$ & $0 \%$ & $1 \%$ & $0 \%$ & $6 \%$ & $0 \%$ & $0 \%$ & $0 \%$ & $1 \%$ & $1 \%$ & $1 \%$ \\
\hline
\end{tabular}


autocitam, eles também estão citando muito a própria instituição. Por outro lado, a comparação dessas duas análises revela diferenças sutis entre as duas classificações, mostrando que algumas instituições apresentam elevada incidência de citações à própria instituição mesmo quando os autores não se autocitam tanto, como se nota nos casos de instituições como a FGV-EAESP e a UFPB - em que a ocorrência de três ou mais citações à instituição é igual a $27 \%$ e $29 \%$ respectivamente.

\section{Intensidade e representatividade de autocitação e de citação à própria instituição}

Um aspecto importante que deixou de se refletir: o quanto essas autocitações ou citações à própria instituição representam do total de obras citadas em cada artigo. Em outras palavras, há uma grande diferença se um autor faz três autocitações em um texto com um total de nove referências, ou se um autor faz as mesmas três autocitações em um texto com um total de 30 referências.

Tabela 6 - Incidência de autocitações - \% de artigos com múltiplas autocitações - classificação por instituição de origem do autor.

\begin{tabular}{|c|c|c|c|c|c|c|c|c|c|c|c|c|}
\hline \multirow{3}{*}{$\begin{array}{c}\text { INSTITUIÇÃO } \\
\text { DE ORIGEM } \\
\text { DO AUTOR }\end{array}$} & \multicolumn{6}{|c|}{ TOTAL DE ARTIGOS } & \multicolumn{6}{|c|}{ ARTIGOS DE AUTORES C/ PRODUÇÃO ANTERIOR } \\
\hline & \multicolumn{6}{|c|}{$\mathrm{N}^{0}$ DE AUTOCITAÇÕES POR ARTIGO } & \multicolumn{6}{|c|}{ No DE AUTOCITAÇÕES POR ARTIGO } \\
\hline & 0 & 1 & 2 & 3 ou + & 4 ou + & $5 \mathrm{ou}+$ & 0 & 1 & 2 & 3 ou + & $4 \mathrm{ou}+$ & 5 ou + \\
\hline UNB & $37 \%$ & $11 \%$ & $0 \%$ & $53 \%$ & $53 \%$ & $42 \%$ & $0 \%$ & $17 \%$ & $0 \%$ & $83 \%$ & $83 \%$ & $67 \%$ \\
\hline UFRN & $44 \%$ & $50 \%$ & $0 \%$ & $6 \%$ & $6 \%$ & $6 \%$ & $0 \%$ & $89 \%$ & $0 \%$ & $11 \%$ & $11 \%$ & $11 \%$ \\
\hline UFMG & $51 \%$ & $24 \%$ & $10 \%$ & $14 \%$ & $9 \%$ & $6 \%$ & $31 \%$ & $34 \%$ & $14 \%$ & $20 \%$ & $12 \%$ & $9 \%$ \\
\hline UFPB & $57 \%$ & $29 \%$ & $0 \%$ & $14 \%$ & $14 \%$ & $14 \%$ & $40 \%$ & $40 \%$ & $0 \%$ & $20 \%$ & $20 \%$ & $20 \%$ \\
\hline USP & $57 \%$ & $22 \%$ & $11 \%$ & $9 \%$ & $4 \%$ & $0 \%$ & $39 \%$ & $32 \%$ & $16 \%$ & $13 \%$ & $5 \%$ & $0 \%$ \\
\hline UFRGS & $60 \%$ & $10 \%$ & $21 \%$ & $9 \%$ & $4 \%$ & $0 \%$ & $33 \%$ & $18 \%$ & $35 \%$ & $15 \%$ & $8 \%$ & $0 \%$ \\
\hline UFBA & $60 \%$ & $30 \%$ & $0 \%$ & $10 \%$ & $0 \%$ & $0 \%$ & $27 \%$ & $55 \%$ & $0 \%$ & $18 \%$ & $0 \%$ & $0 \%$ \\
\hline UFSC & $65 \%$ & $24 \%$ & $12 \%$ & $0 \%$ & $0 \%$ & $0 \%$ & $33 \%$ & $44 \%$ & $22 \%$ & $0 \%$ & $0 \%$ & $0 \%$ \\
\hline FGV-EBAPE & $69 \%$ & $0 \%$ & $15 \%$ & $15 \%$ & $0 \%$ & $0 \%$ & $0 \%$ & $0 \%$ & $50 \%$ & $50 \%$ & $0 \%$ & $0 \%$ \\
\hline FGV-EAESP & $73 \%$ & $7 \%$ & $20 \%$ & $0 \%$ & $0 \%$ & $0 \%$ & $64 \%$ & $9 \%$ & $27 \%$ & $0 \%$ & $0 \%$ & $0 \%$ \\
\hline UFPR & $75 \%$ & $25 \%$ & $0 \%$ & $0 \%$ & $0 \%$ & $0 \%$ & $0 \%$ & $100 \%$ & $0 \%$ & $0 \%$ & $0 \%$ & $0 \%$ \\
\hline UFPE & $83 \%$ & $17 \%$ & $0 \%$ & $0 \%$ & $0 \%$ & $0 \%$ & $25 \%$ & $75 \%$ & $0 \%$ & $0 \%$ & $0 \%$ & $0 \%$ \\
\hline PUC-RJ & $93 \%$ & $0 \%$ & $7 \%$ & $0 \%$ & $0 \%$ & $0 \%$ & $80 \%$ & $0 \%$ & $20 \%$ & $0 \%$ & $0 \%$ & $0 \%$ \\
\hline
\end{tabular}

Tabela 7 - Incidência de citações à própria instituição.

\begin{tabular}{|l|c|c|c|c|c|c|}
\hline \multirow{2}{*}{$\begin{array}{l}\text { INSIITUIÇÃO } \\
\text { DO AUTOR }\end{array}$} & \multicolumn{7}{|c|}{ NÚMERO DE CITAÇÕES À PRÓPRIA INSTITUIÇÃO } \\
\hline & 0 & 1 & 2 & 3 ou + & 4 ou + & 5 ou + \\
\hline UNB & $37 \%$ & $5 \%$ & $16 \%$ & $42 \%$ & $42 \%$ & $42 \%$ \\
\hline UFRN & $38 \%$ & $13 \%$ & $19 \%$ & $31 \%$ & $19 \%$ & $19 \%$ \\
\hline UFPB & $43 \%$ & $14 \%$ & $14 \%$ & $29 \%$ & $29 \%$ & $29 \%$ \\
\hline FGV-EAESP & $53 \%$ & $13 \%$ & $7 \%$ & $27 \%$ & $20 \%$ & $7 \%$ \\
\hline UFBA & $55 \%$ & $15 \%$ & $10 \%$ & $20 \%$ & $10 \%$ & $10 \%$ \\
\hline UFSC & $59 \%$ & $0 \%$ & $12 \%$ & $29 \%$ & $18 \%$ & $18 \%$ \\
\hline FGV-EBAPE & $62 \%$ & $0 \%$ & $8 \%$ & $31 \%$ & $15 \%$ & $0 \%$ \\
\hline USP & $70 \%$ & $4 \%$ & $7 \%$ & $19 \%$ & $13 \%$ & $9 \%$ \\
\hline PUC-RJ & $71 \%$ & $14 \%$ & $0 \%$ & $14 \%$ & $7 \%$ & $0 \%$ \\
\hline UFPE & $72 \%$ & $11 \%$ & $11 \%$ & $6 \%$ & $6 \%$ & $0 \%$ \\
\hline UFRGS & $73 \%$ & $4 \%$ & $3 \%$ & $19 \%$ & $13 \%$ & $10 \%$ \\
\hline UFMG & $76 \%$ & $2 \%$ & $3 \%$ & $19 \%$ & $15 \%$ & $13 \%$ \\
\hline UFPR & $88 \%$ & $13 \%$ & $0 \%$ & $0 \%$ & $0 \%$ & $0 \%$ \\
\hline
\end{tabular}


A Tabela 8 permite visualizar que muitas instituições parecem ter "cultura" de autocitação e citação à própria instituição de elevada intensidade. Isso significa que os autores dessas instituições parecem ver como natural que 15 ou 20\% das citações em seus trabalhos citem a si próprios, ou que 15, 25 ou até $40 \%$ das referências feitas sejam a autores de suas próprias instituições. Convém lembrar que a medida de autocitação e de citação à própria instituição da Tabela 8 apresenta-se diluída pelo total de autores da instituição no período. Ou seja, mesmo aqueles que não tinham o que citar à época da publicação estão sendo considerados na contagem do total de autocitações feitas, aumentando o denominador e, portanto, diminuindo o quociente da equação.

É verdade que toda análise e crítica feita até agora sobre alta incidência de autocitação e citação à própria instituição precisa ser, na medida do possível, relativizada. Por exemplo, seria possível argumentar que as instituições que dominam um campo de pesquisa apresentem, justificadamente, alta incidência e intensidade de autocitação e citação à própria instituição. Nesse caso, ainda seria possível argumentar que, uma vez que alguns autores dessa instituição detiveram uma proporção importante da produção nacional sobre um determinado tema, não lhes restaria muita opção a não ser citar a si próprios. Esse é um ponto válido mas lamentavelmente quase impossível de controlar objetiva ou estatisticamente em amostras tão populosas e de temáticas tão diversificadas como a que foi analisada.

Por outro lado, é também verificável que esse tipo de alta intensidade de autocitação aparece não apenas em instituições com elevada produção, mas também em instituições com menor volume de trabalhos passíveis de citação, como mostra a Tabela 4. Seja como for, acreditase que, como muitos desses novos programas parecem estar sendo formados de egressos dos programas maiores ou mais tradicionais, a idéia de que esse padrão de comportamento auto-referente possa estar sendo difundido a partir de pesquisadores e de ex-alunos dos principais programas de pós-graduação do país pode ganhar força. Seria mais um motivo para provocar o debate, no próprio âmbito da Anpad, sobre comportamentos "adequados" de autoria e referência, e sobre o combate à potencial endogenia acadêmica em nossa área.

\section{CONCLUSÕES}

De forma geral, os resultados da pesquisa apontam para problemas intrincados e limitações estruturais do desen- volvimento da produção acadêmica da área de Recursos Humanos na década de 1990. No entanto, trabalhos e pesquisas como os que foram apreendidos neste artigo poderiam ser acusados de se dedicarem à contemplação retrospectiva e passiva do desenvolvimento de áreas de conhecimento. De fato, é muito mais fácil apontar padrões de comportamento e ação em amplas bases de dados - e a partir daí criticar a área, seus problemas e desafios, seus autores - do que apontar caminhos de superação desses problemas e de melhoria do campo como um todo.

Em vista disso, nesta seção, além de discutir os resultados da pesquisa como um todo, procurar-se-á concluir o trabalho apontando sugestões ao campo para lidar com os principais problemas e limitações apontados na produção de RH da década de 1990 no Enanpad. Como dito anteriormente, as sugestões a seguir advêm da combinação da análise quantitativa acima com a análise qualitativa dos artigos usando a base disponível do trabalho de Caldas et al. (2002).

Dos achados da pesquisa, o primeiro foi a forte incidência de citações a textos gerencialistas e de fontes ins-

Tabela 8 - Intensidade/representatividade de autocitações por instituição - \% de autocitações e citações à própria instituição em relação ao total de obras citadas por artigo.

\begin{tabular}{|l|c|c|}
\hline INSTITUIÇÃO & AUTOCITAÇÕES & CITAÇÕES À PRÓP. INST. \\
\hline UEPB & $18 \%$ & $40 \%$ \\
\hline ESAL & $17 \%$ & $33 \%$ \\
\hline MACKENZIE & $13 \%$ & $25 \%$ \\
\hline UFSCAR & $21 \%$ & $21 \%$ \\
\hline UNB & $16 \%$ & $21 \%$ \\
\hline UFC & $20 \%$ & $20 \%$ \\
\hline IMES & $0 \%$ & $19 \%$ \\
\hline UCAM & $9 \%$ & $18 \%$ \\
\hline UFMT & $0 \%$ & $18 \%$ \\
\hline CRT & $12 \%$ & $18 \%$ \\
\hline USP & $5 \%$ & $16 \%$ \\
\hline UFMG & $5 \%$ & $15 \%$ \\
\hline UFRGS & $5 \%$ & $13 \%$ \\
\hline UFPB & $4 \%$ & $13 \%$ \\
\hline UFRN & $4 \%$ & $13 \%$ \\
\hline UFSC & $3 \%$ & $12 \%$ \\
\hline PUC-RS & $9 \%$ & $11 \%$ \\
\hline FUMECMG & $0 \%$ & $11 \%$ \\
\hline FGV-EAESP & $2 \%$ & $10 \%$ \\
\hline PUC-SP & $5 \%$ & $10 \%$ \\
\hline UFRJ & $6 \%$ & $10 \%$ \\
\hline UNISINOS & $8 \%$ & $10 \%$ \\
\hline & & \\
\hline
\end{tabular}


titucionais ou não acadêmicas. De fato, a citação de textos (muitas vezes sem sequer a um autor declarado) veiculados em publicações como Exame e HSM como base de "fundamentação" dos trabalhos é, por si só, um atestado de que boa parte da área carece de fundamentação teórica consistente. Talvez também possa derivar daí a popularidade dessas publicações como fonte de "conhecimento". Por esse motivo, a primeira sugestão à área é revisar os critérios de avaliação, aumentando a seletividade nos processos de revisão de artigos submetidos aos principais veículos (periódicos e congressos) nacionais, dificultando o aceite de trabalhos com base conceitual academicamente questionável.

Uma segunda linha de resultados mostrou a intensa pulverização de fontes de referências (especialmente periódicos e congressos) que foram citadas na área na década de 1990. Ficou clara a utilização excessiva de livros em relação a artigos científicos, bem como a grande pulverização de fontes mesmo dentre os artigos acadêmicos, tendo, os mais representativos, não mais do que 3\% das citações (no caso da RAE e dos periódicos nacionais), e de não mais do que $1,5 \%$, no caso dos periódicos estrangeiros. A natureza razoavelmente consistente de utilização intensiva de muitos dos principais veículos nacionais pelos programas mostra que definir o que é um "bom" ou "mal" periódico ou congresso, e a partir daí o conceito do que "vale a pena" ser lido e conhecido, é muito dependente do processo cultural e de socialização vivido em cada programa. Isso leva à segunda sugestão: discutir os critérios e empreender uma revisão comparativa (estruturada) da qualidade e da extensão de impacto da publicação nos veículos nacionais.

Em essência, a sugestão anterior sugere a possibilidade de ter chegado o momento, na área de administração, de se estruturar melhor a análise comparada de qualidade e a extensão do impacto da publicação em cada um de seus veículos. Se o campo não empreender tal esforço, ao que tudo indica, cada programa continuará com sua versão do que vale a pena ou não ler.

O outro resultado importante é o que demonstra a grande concentração de autores citados em poucos programas de pós-graduação. Como discutido anteriormente, esse tipo de concentração excessiva pode ameaçar a diversidade de referências da área como um todo, o que, por sua vez, constitui um dos principais direcionadores de endogenia acadêmica. Assim, a terceira sugestão é facilitar o acesso à pesquisa interinstitucional, incentivar a intensificação do intercâmbio e o aumento de diversidade institucional das referências.

Como campo de conhecimento, a área de RH não pode deixar de influenciar o processo que hoje leva cada instituição e seus autores a ignorar boa parte do que os demais produzem. Mecanismos de acesso à pesquisa feita em outros programas e os meios para financiá-los podem ser, portanto, tópicos frutíferos de discussão na área nos próximos anos.

Um próximo resultado, que confirma pesquisas anteriores, aponta a tendência predominante à citação estrangeira e à própria instituição na maioria dos programas. $\mathrm{Na}$ prática, isso implica no risco da endogenia em campos científicos, pois, para produzir um trabalho científico, é necessário mostrar o estado da arte e, portanto, que o trabalho apresenta conteúdo incremental (Fujigaki, 1998). Quando ocorre a endogenia, isto é, quando a rede de trabalhos conhecidos e que servem de base para evolução é pequena e há pouco relacionamento e pouco incremento de conhecimento em uma determinada área, pode-se dizer que essa área é suscetível à entropia. Esse tipo de processo, pensado no contexto brasileiro, oferece mais duas possibilidades de sugestão à área.

Primeiro, facilitar e incentivar - via revisão dos critérios de avaliação dos programas, ou dos recentemente propostos processos de certificação institucional - a limitação da referência à própria instituição e aumento de redes interinstitucionais. Segundo, viabilizar e incentivar a formação de programas e linhas de pesquisa, bem como programas de pós-graduação interinstitucionais, que aproximem e disseminem mais a pesquisa nacional e promovam o intercâmbio de referências.

Deixa-se claro, em todo este artigo, o fato de que os altos níveis de referência estrangeira, autocitação e citação à própria instituição que foram encontrados no estudo são dignos de preocupação. Não significa, entretanto, que qualquer ocorrência de referência estrangeira automaticamente designe estrangeirismo, nem que qualquer autocitação indique, necessariamente, narcisismo ou ufanismo acadêmico.

No caso da auto-referência, e analogamente ao que foi discutido sobre o excesso de referência estrangeira, o problema não é a simples ocorrência, mas a incidência (no sentido de volume), a constância (no sentido de hábito de autores e instituições ao longo do tempo), e a intensidade (no sentido de representatividade da autoreferência no conjunto das obras citadas ou consultadas). É por esse motivo que as conclusões e análises acima se concentram não nos casos de ocorrência mínima ou dispersa de auto-referências, mas na sua alta incidência, constância e intensidade médias, na amostra estudada.

No que tange a esses altos níveis de autocitação e citação à própria instituição entre as instituições represen- 
tadas na amostra, os dados do estudo evidenciam certa coerência por programa, sugerindo padrões de comportamento aprendidos dentro de cada instituição, que são propagados na socialização de novos docentes, na formação de egressos (críticas à falta de "publicação da casa" em defesas de dissertações e teses, etc.) e assim por diante. Duas sugestões à área se apresentam a partir dessa constatação. Primeiro, a de se promoverem debates, talvez no âmbito do Enanpad, do que seriam padrões "adequados" de comportamento de autoria e de referência para o nosso contexto, e quais os procedimentos e metodologias corretos para medir e limitar autocitação e citações da própria instituição no campo. Como essas discussões ultrapassam os limites da área de $\mathrm{RH}$, seria conveniente promover trabalhos de investigação nas demais áreas, como o aqui empreendido. Por fim, os resultados em torno da representatividade das autocitações é preocupante, e parece mostrar padrões razoavelmente consistentes em cada programa, como se esse tipo de comportamento fosse reproduzido em seus egressos nas suas instituições de destino. Surge daí nossa última sugestão à área, que se refere à necessidade de se discutirem, no âmbito do Enanpad, as limitações de eficácia do padrão autocentrado de autoria e referência, bem como as formas de combater a endogenia que o excesso de autocitações ou citações "do próprio quintal" podem produzir em nossa área.

Tomando-as como um todo, as conclusões sobre a pesquisa e as sugestões acima sugerem que, mais do que mapear limitações, pesquisas como esta devem ativamente engajar-se, mesmo pela provocação e por sugestões, na indicação de caminhos e soluções para os problemas de desenvolvimento que apontam. Este artigo não se esquivou de fazer tais indicações, e espera-se que ajude num debate que outros autores e trabalhos já começaram na área e no campo de Administração.

A melhor notícia é que boa parte das soluções está ao nosso alcance: depende quase exclusivamente dos próprios autores e pesquisadores atuantes na área. Depende de nós, a criação de critérios mais rigorosos de seleção de trabalhos e de avaliação de veículos, a criação de códigos de conduta para autores e instituições na autoria e citação de referências, como também a criação e difusão de balanços sobre o que fizemos e como fizemos. Quando falamos dos problemas da área, não falamos de outrem: falamos todos do que nós fizemos, e do que poderíamos ter feito de modo diferente ou melhor. Isso torna mais palatáveis e superáveis os problemas e limitações estruturais que encontramos no desenvolvimento recente da área, pois seu tratamento e superação dependerão, em última análise, de nossa própria ação. É claro que as sugestões feitas estão longe de ser exaustivas ou simples. No entanto, sabemos que o desenvolvimento e a melhoria de campos científicos é uma tarefa gradual e coletiva. E é por isso que este é apenas mais um passo em uma área que continuamente se descobre e redescobre.

\section{REFERÊNCIAS BIBLIOGRÁFICAS}

ARKADER, R. A pesquisa científica em gerência de operações no Brasil. Revista de Administração de Empresas, v. 43, n. 1, p. 70-79, 2003.

AZZONI, C. R. "Clássicos" da literatura econômica brasileira: trabalhos e autores mais citados nas nossas revistas acadêmicas. Economia Aplicada, v. 2, n. 4, p. 771-780, 1998.

AZZONI, C. R. Desempenho das revistas e dos departamentos de economia brasileiros segundo publicações e citações recebidas no Brasil. Economia Aplicada, v. 4, n. 4, p. 786, 2000

CHANDY, P. R.; WILLIAMS, T. G. The impact of journals and authors on international business research: a citation analysis of JIBS articles. Journal of International Business Studies, v. 25 n. 4, p. 715-728. 1994.

COLE, J. R. E.; COLE, S. Social Stratification in Science. Chicago: University of Chicago, 1973.

FISCHER, T. A formação do administrador brasileiro na década de 90: crise, oportunidade e inovações nas propostas de ensino. Revista de Administração Pública, v. 27, n. 4, p. 11-20, 1993.

FUJIGAKI, Y. The citation system. Scientometrics, n. 43, p. 77-85, 1988.

GARFIELD, E. Citation indexes for science. Science, n. 122, p. 108, 1955.

GARFIELD, E. Citation Indexing: Its Theory and Application in Science, Technology and Humanities. New York: Willey, 1979.

HOPPEN, N.; AUDY, J. L. N.; ZANELA, A. I. C.; CANDOTTI, C. T; SANTOS, A. M.; SCHEID, R.; PERIN, M. G.; MECCA, M. S.; PETRINI, M. Sistemas de informação no Brasil: uma análise dos artigos científicos dos anos 90. In: ENCONTRO ANUAL DA ASSOCIAÇÃO DOS PROGRAMAS DE PÓS-GRADUAÇÃO EM ADMINISTRAÇÃO, 22., 1998, Foz do Iguaçu. Anais... Foz do Iguaçu: Anpad, 1998. Administração da Informação.

KEINERT, T. M. O que é administração pública no Brasil? In: ENCONTRO ANUAL DA ASSOCIAÇÃO DOS PROGRAMAS DE PÓS-GRADUAÇÃO EM ADMINISTRAÇÃO, 24., 2000, Florianópolis. Anais... Florianópolis: Anpad, 2000. Marketing

KOSTOFF, R. N. The use and misuse of citation analysis in research evaluation. Scientometrics, v. 43, p. 27-43, 1998.

LEAL, R.; OliVEIRA, J.; SOLURI, A. Perfil da pesquisa em finanças no Brasil. Revista de Administração de Empresas, v. 43, n. 1, p. 91-104, 2003. 
LEYDESDORFF, L. Theories of citation? Scientometrics, v. 43, p. 5-25, 1998.

MACHADO DA SILVA, C. L.; CUNHA, V. C.; AMBONI, N. Organizações: o estado da arte da produção acadêmica no Brasil. In: ENCONTRO ANUAL DA ASSOCIAÇÃO DOS PROGRAMAS DE PÓS-GRADUAÇÃO EM ADMINISTRAÇÃO, 14., 1990, Florianópolis. Anais...Florianópolis: Anpad, 1990.

MACROBERTS, M. H.; MACROBERTS, B. R. Problems of citation analysis. Scientometrics, v. 36, p. 435-444. 1996.

MARTYN, J. An examination of citation indexes Aslib. Proceedings, v. 17, n. 6, p. $184,1965$.

MERTON, R. K. Foreword. In: GARFIELD, E. Citation Indexing - Its Theory and Application in Science, Technology, and the Humanities. Philadelphia: ISI, 1983.

PERIN, M. G.; SAMPAIO, C. H.; FROEMMING, L. M. S.; LUCE, F. B. A pesquisa survey em artigos de marketing nos Enanpads da década de 90. In: ENCONTRO ANUAL DA ASSOCIAÇÃO DOS PROGRAMAS DE PÓSGRADUAÇÃO EM ADMINISTRAÇÃO, 24, 2000, Florianópolis. Anais... Florianópolis: Anpad, 2000.

QUINTELLA, R. Encontro nacional da Anpad x Meeting of AOM: Lições, questionamentos e especulações. Revista de Administração de Empresas. v. 43, n. 3, p. 107-115. 2003.

TONELLI, M.; CALDAS, M.; LACOMBE, B.; TINOCO, T. Produção acadêmica em Recursos Humanos no Brasil: 1991-2000. Revista de Administração de Empresas, v. 43, n. 1, p. 105-122, 2003.

VANTI, N. Da bibliometria à webometria: uma exploração conceitual dos mecanismos utilizados para medir o registro da Informação e a difusão do conhecimento. Ciência da Informação, v. 31, n. 2, p. 152-162, 2002.

VERGARA, S. C.; CARVALHO JR., D. S. Nacionalidade dos autores referenciados na literatura brasileira sobre organizações. In: ENCONTRO ANUAL DA ASSOCIAÇÃO DOS PROGRAMAS DE PÓS-GRADUAÇÃO EM ADMINISTRAÇÃO, 19., 1995, João Pessoa. Anais... Rio de Janeiro: Anpad, 1995. Organizações.
VERGARA, S. C.; CARVALHO JR., D. S. Refletindo sobre as possíveis conseqüências da análise organizacional apoiada em referências estrangeiras. Revista de Administração Pública, v. 30, n. 6, 1996.

VERGARA, S.; PINTO, M. C. S. Nacionalidade das referências teóricas em análise organizacional: um estudo das nacionalidades dos autores referenciados na literatura brasileira. In: ENCONTRO ANUAL DA ASSOCIAÇÃO DOS PROGRAMAS DE PÓS-GRADUAÇÃO EM ADMINISTRAÇÃO, 1., 2000, Curitiba. Anais... Curitiba: Anpad, 2000.

VIEIRA, F. G. Narciso sem espelho: a publicação brasileira de marketing. Revista de Administração de Empresas, v. 43, n. 1, p. 81-90, 2003.

VIEIRA, F. G. D. Ações empresariais e prioridades de pesquisa em marketing: tendências no Brasil e no mundo segundo a percepção dos acadêmicos brasileiros. In: ENCONTRO ANUAL DA ASSOCIAÇÃO DOS PROGRAMAS DE PÓS-GRADUAÇÃO EM ADMINISTRAČ̃̃O, 23., 1999, Foz do Iguaçu. Anais... Foz do Iguaçu: Anpad, 1999. Marketing.

VIEIRA, F. G. D. Panorama acadêmico-científico e temáticas de estudos de marketing no Brasil. In: In: ENCONTRO ANUAL DA ASSOCIAÇÃO DOS PROGRAMAS DE PÓS-GRADUAÇÃO EM ADMINISTRAÇÃO, 24., 2000, Florianópolis. Anais... RJ : Anpad, 2000. Marketing.

WOOD JR, T.; PAULA, A. Pop-management: pesquisa sobre as revistas populares de gestão no Brasil. 2002. In: ENCONTRO ANUAL DA ASSOCIAÇÃO DOS PROGRAMAS DE PÓS-GRADUAÇÃO EM ADMINISTRAÇÃO, 26., 2002, Salvador. Anais... Salvador: Anpad, 2002

WORMELL, I. Informetria: explorando bases de dados como instrumentos de análise. Ciência da Informação, v. 27, n. 2, p. 210-216, 1998.

\section{NOTAS}

Os autores gostariam de reconhecer a colaboração de Maria José Tonelli e Beatriz Lacombe, que aceitaram compartilhar com os autores desta pesquisa a base de dados que usaram em seu artigo (Caldas, Tonelli e Lacombe, 2002) e alguns de seus elementos qualitativos que permitiram a comparabilidade dos resultados dos dois trabalhos e o enriquecimento das sugestões aqui apresentadas, e lhes agradecer por isso. Gostaríamos ainda de agradecer a colaboração de Rebeca Chu no levantamento dos dados utilizados nessa pesquisa.

Este trabalho foi realizado com apoio do NPP, da FGV-EAESP.

\section{Artigo recebido em 30.09.2003. Aprovado em 15.02.2004.}

\section{Miguel P. Caldas}

Associate Professor of International Business na Loyola University New Orleans. Interesses de pesquisa em teoria das organizações, cultura organizacional, mudança e design organizacional.

E-mail: mpcaldas@loyno.edu

Endereço: 6363 St. Charles Avenue, Box 15. New Orleans, LA, USA, 70118.

\section{Tatiana Tinoco}

Mestranda em Administração de Empresas pela FGV-EAESP. Interesses de pesquisa em recursos humanos, teoria das organizações e ensino e pesquisa em Administração.

E-mail: tatianat@gvmail.br

Endereço: Av. Nove de Julho, 2029 9ª andar - Bela Vista - São Paulo - SP, 01313-902. 